\title{
FINANCIRANJE POSLOVANJA PODUZEĆA EMISIJOM DIONICA - PREGLED I TRENDOVI U REPUBLICI HRVATSKOJ
}

\author{
Izv. prof. dr. sc. Ante Rončević \\ Sveučilište Sjever \\ Trg dr. Žarka Dolinara 1, 48000 Koprivnica, Hrvatska \\ Telefon: +385 91 1702964, e-mail: aroncevic@unin.hr \\ Josip Vuković, univ. spec. oec., predavač \\ Sveučilište Sjever \\ Trg dr. Žarka Dolinara 1, 48000 Koprivnica, Hrvatska \\ Telefon: +38598 9100084, e-mail: jvukovic@unin.hr \\ Doc. dr. sc. Marina Gregorić \\ Sveučilište Sjever \\ Trg dr. Žarka Dolinara 1, 48000 Koprivnica, Hrvatska \\ Telefon: +385 99 4040164, e-mail: magregoric@unin.hr
}

\section{SAŽETAK}

Svoj rast i razvoj poduzeća financiraju na različite načine ovisno o tome u kojoj fazi poslovanja se poduzeće nalazi. U fazi zrelosti, odnosno ekspanzije, tri su prevladavajuća načina na koje se poduzeće može financirati: 1) iz zadržane dobiti, 2) financiranjem putem duga, te, 3) izdavanjem dionica. Predmet istraživanja ovoga rada su dionička društva i financiranje putem izdavanja dionica. $U$ radu su prikazana glavna obilježja $i$ načini financiranja poslovanja putem emisije dionica. Analiziraju se vrste dionica, proces izdavanja i sudionici te se opisuju elementi i procesi inicijalne i sekundarne javne ponude dionica. Financiranje poslovanja poduzeća putem povlaštenih dionica, koje je relativno slabo zastupljeno kao način financiranja, prikazano je na konkretnom primjeru kupnje povlaštenih dionica Podravke d.d. od strane Europske banke za obnovu i razvoj. U radu su također definirane inicijalne i sekundarne javne ponude dionica u Republici Hrvatskoj u razdoblju od 2006 do danas.

Ključne riječi: financiranje poslovanja poduzeća, vrijednosni papiri, dionice, povlaštene dionice, burza, inicijalna javna ponuda, sekundarna javna ponuda 


\section{UVOD}

Svako poduzeće osnovano je s potrebom da se ostvari neka ideja, da se realizira neki poduzetnički pothvat, da se pruže određene usluge ili prodaju neki proizvodi. Cilj je da poduzeće kroz te aktivnosti ostvari dobre financijske rezultate koji će onda na kraju i njegovom vlasniku donijeti neku ekonomsku korist i dobit. Pod pretpostavkom da je poduzeće uspješno u svojim aktivnostima, da se etabliralo na tržištu, ostvarivat će se preduvjeti za daljnji rast i razvoj. Daljnji rast i razvoj zahtijevat će dodatna financijska sredstva, kojima će se financirati tekuće i razvojne potrebe poduzeća.

Potrebe za financiranjem kod proizvodnog poduzeća odnosit će se na moguće proširenje proizvodnih kapaciteta u vidu novog pogona ili nove tvornice koju će trebati izgraditi i u nju ugraditi novu opremu. Predmet financiranja mogu biti i troškovi akvizicije, troškovi marketinga ili obrtnih sredstva za kupnju sirovina i materijala koja će omogućiti daljnje nesmetano poslovanje (Orsag, Dedi, 2011, str. 14-15).

\subsection{Predmet istraživanja}

Predmet istraživanja ovog rada su vrste i načini financiranja poduzeća. Financiranje je jedan od najvažnijih elemenata u cjelokupnom procesu poslovanja poduzeća. Pravilna struktura i efikasno upravljanje izvorima financiranja izuzetno su važni za opstanak, razvoj i rast poduzeća. Posebna pozornost obratit će se na financiranje poduzeća putem emisije vrijednosnih papira, prije svega dionica, te će se prikazati vrste dionica, s posebnim osvrtom na povlaštene, preferencijalne dionice.

\subsection{Ciljevi istraživanja}

Ciljevi istraživanja provedenog u ovome radu su definirati vrste i načine financiranja poduzeća, analizirati vrste dionica s posebnim osvrtom na prikaz povlaštenih dionica na primjeru povlaštenih dionica Europske banke za obnovu i razvoj (EBRD), sa sjedištem u Londonu, u Podravki d.d., Koprivnica, utvrditi proces izdavanja dionica te istražiti inicijalne (IPO) i sekundarne (SPO) javne ponude dionica u Hrvatskoj u razdoblju od 2006. do 2020. godine.

\subsection{Metode istraživanja}

$U$ radu su korištene metode analize i znanstvene sinteze te povijesna metoda. Metoda deskripcije i metoda klasifikacije korištene su s ciljem opisa i pregleda pojma i odrednica financiranja. Metoda komparacije omogućuje usporedbu između različitih instrumenata te metoda indukcije i dedukcije.

\section{VRSTE FINANCIRANJA}

Oblik i način financiranja poduzeća, dioničkog društva, ovise o tome u kojoj se fazi poslovanja poduzeće nalazi. Različite su potrebe poduzeća na samom početku poslovanja, u fazi ekspanzije, a drugačije u fazi stabilnog poslovanja kada je kompanija zrela. Na samom 
početku poslovanja poduzeća se financiraju uglavnom vlastitim kapitalom (eng. equity), koji dolazi iz vlastite ušteđevine, pozajmnica od prijatelja ili rodbine (Damodaran, 1997, str. 407).

U fazi rasta, odnosno rapidnog razvoja, potrebe za financiranjem su veće, dobit se tek treba ostvariti i u tom razdoblju poduzeća svoje potrebe za financiranjem pronalaze u „venture capital“ fondovima ili u izdavanju dionica. Kada se poduzeće etabliralo na tržištu i kada ima stabilno poslovanje i prihode te zadovoljavajuću razinu bilance i novčanog toka, ono se može osloniti ili na kreditno financiranje od strane banaka ili iz zadržane dobiti ili kombinirati ta dva modela.

Financiranje razvoja poduzeća se stoga može prikazati prema fazama razvoja:

(i) eksperimentalna ili sjemenska faza (eng. seed)

(ii) početna faza (eng. start-up)

(ii) faza ekspanzije (eng. expansion)

(iv) faza dokapitalizacije (eng. capital increase)

(i) faza preuzimanja (eng. buyout, prodaja većinskog udjela poduzeća)

\section{Slika 1. Financiranje razvoja poduzeća}

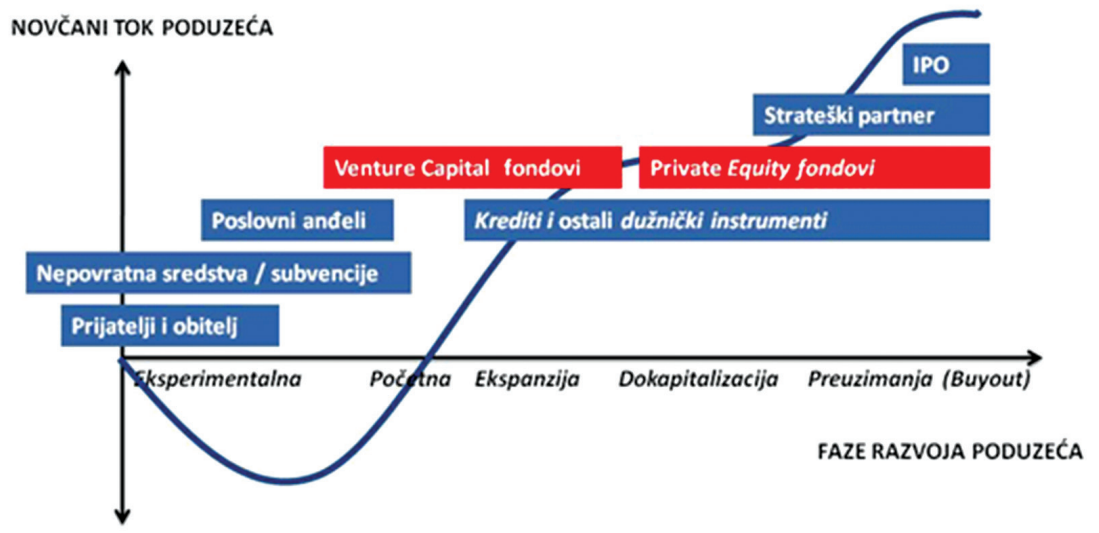

Izvor: CVCA (2018.) Financiranje malih i srednjih poduzeća [online]. Dostupno na: http://www.cvca.hr/zastope-i-venture-capital/rjecnik-termina/

Tri su uobičajena, prevladavajuća vida ili načina na koja poduzeće može financirati daljnji rast i razvoj: i) iz zadržane dobiti, ii) financiranje putem duga (uzimanjem kredita ili izdavanjem obveznica) te iii) izdavanjem dionica.

Financiranje putem zadržane dobiti. Nakon podmirenja svih troškova poslovanja, poduzeće, ako je uspješno, uspjet će na kraju poslovnog razdoblja ostvariti određenu dobit, odnosno profit. Ako se ne želi zaduživati, svoje daljnje poslovanje može financirati iz zadržane dobiti (Orsag, 1997, str. 84-85). Razlozi zašto se neka poduzeća odlučuju na financiranje iz zadržane dobiti leže u činjenici da su neki vlasnici poduzeća neskloni zaduživanju, bilo kakvom obliku kreditnog odnosa i obveza. To može biti kratkoročna odluka, za neko 
kraće razdoblje u poslovanju poduzeća, a kod nekih poduzeća to može trajati i dulje. Neka poduzeća nisu nesklona samo kreditnom zaduženju, nesklonost se odnosi i na financiranje putem izdavanja dionica. Tom vidu financiranja i dalje je nesklon jako veliki broj poduzeća u Republici Hrvatskoj (Kolković, Turuk, Turčić, 2019, str. 10).

Financiranje putem duga (uzimanjem kredita, izdavanjem obveznica i dr.). Kako poduzeće raste, potrebe za financiranjem se povećavaju, standardni način financiranja tog rasta je odlazak u banku i dogovaranje kredita, kreditnog aranžmana. Banke standardno financiraju obrtna sredstva, manje investicijske projekte, proširenje kapaciteta, uvozno-izvozne poslove. Istraživanja pokazuju da što je razvijeniji bankovni sektor, to je i sklonost poduzeća zaduživanju veća, kao i zaduženost poduzeća (Pepur, Ćurak, Poposki, 2016, str. 511). Hrvatski bankovni sektor je prilično razvijen i jedan je od najnaprednijih i najsofisticiranijih sektora u Republici Hrvatskoj. Omogućava široku paletu proizvoda i usluga poduzećima u Republici Hrvatskoj te je time i jedan od najzastupljenijih kanala financiranja. Drugi vid dužničkog financiranja, koji je primjereniji za veća poduzeća, izdavanje je obveznica. Izdavanje dionica je sofisticiraniji, zahtjevniji način financiranja poduzeća, dioničkih društava.

\section{DIONICE I VRSTE DIONICA - PRIMJER POVLAŠTENIH DIONICA}

Dionica je vlasnički vrijednosni papir koji predstavlja pravo vlasništva u određenom dioničkom društvu. Razlikujemo dva osnovna roda dionica: i) redovne ili obične dionice i ii) povlaštene ili preferencijalne dionice (Orsag, 1997, str. 325).

Redovne dionice daju imateljima pravo glasa na glavnoj skupštini dioničkog društva te pravo na isplatu dijela dobiti (dividendu). Povlaštene dionice imatelju daju neka povlaštena prava u odnosu na imatelje redovnih dionica, npr. pravo na dividendu u unaprijed utvrđenom novčanom iznosu ili u postotku od nominalnog iznosa dionice, pravo prvenstva pri isplati dividende.

Postoje također i vlastite ili trezorske dionice. To su dionice koje je steklo dioničko društvo koje ih je izdalo. Ne nose prava na dividendu i prava glasa dok god ih društvo drži.

Redovne (obične) dionice. Glavne karakteristike redovnih dionica mogu se prikazati kako slijedi: i) kod redovnih dionica ulagačev rizik veći je nego kod bilo kojih drugih vrijednosnih papira koje društvo izdaje, ii) imatelji redovnih dionica imaju najniže pravo prvenstva na zaradu i imovinu, iii) redovna dionica svojim imateljima daje neograničen broj mogućnosti plaćanja dividendi i povećanja cijene, iv) imatelji redovnih dionica imaju kontrolu nad upravljanjem dioničkim društvom, v) dividenda kod redovnih dionica se ne mora isplatiti, a razlozi mogu biti niža nego planirana dobit ili reinvestiranje dobiti da bi se financirao daljnji razvoj (Orsag, 1997, str. 335).

Povlaštene (preferencijalne) dionice. U usporedbi s redovnim dionicama, glavne karakteristike povlaštenih dionica se sljedeće: i) povlaštene dionice u pravilu nemaju pravo glasa, a time niti kontrolu nad upravljanjem društva, ii) povlaštene dionice daju svojim imateljima pravo prvenstva pred dioničarima koji drže redovite dionice u pogledu zarada i imovine u slučaju likvidacije, iii) povlaštene dionice imaju nižu stopu povrata od redovnih dionica jer u odnosu na njih prihvaćaju niži rizik, iii) povlaštene dionice su ograničene iznosom dividendi koje mogu primiti, ostvariti (Orsag, 1997, str. 438). Unutar povlaštenih dionica razlikuje se i nekoliko podvrsta: kumulativna, participativna, konvertibilna i dionica $\mathrm{s}$ mogućnošću otkupa. 
Kumulativne preferencijalne dionice su preferencijalne dionice s kumulativnim pravom na preferencijalne dividende. One nose kumulativno pravo na dividende, pravo da se sve zaostale, dakle neisplaćene zajamčene ili ugovorene dividende na preferencijalne dionice iz prošlosti moraju isplatiti prije isplate bilo kakvih drugih dividendi, kako na obične tako i na druge dionice.

Participativne preferencijalne dionice su preferencijalne dionice koje uz fiksni iznos preferencijalnih dividendi vlasniku osiguravaju i udjel u realiziranim zaradama izdavatelja.

Konvertibilne preferencijalne dionice su preferencijalne dionice koje se mogu konvertirati u neke druge vrijednosne papire izdavatelja ili s izdavateljem povezanog poduzeća.

Preferencijalne dionice s mogućnošću otkupa su specifična vrsta preferencijalnih dionica koje tvrtka izdavatelj mora otkupiti prema uvjetima objavljenim u raspisu emisije na zahtjev njihova vlasnika.

\subsection{Primjer povlaštenih dionica: EBRD-jev udjel u Podravki d.d.}

Povlaštene dionice su vrlo rijetke, odnosno rijetko su izdavane na tržištu kapitala u Republici Hrvatskoj i trenutno ih ima i jako malo kotiranih na Zagrebačkoj burzi. Jedno od rijetkih izdanja koje može ilustrirati na konkretnom primjeru koje sve atribute može imati i nositi povlaštena dionica jest svojedobna kupnja povlaštenih dionica prehrambene industrije Podravke d.d. iz Koprivnice od strane renomirane međunarodne financijske institucije, Europske banke za obnovu i razvoj (EBRD) sa sjedištem u Londonu.

Podravka d.d. je 10. srpnja 1998. godine potpisala Ugovor s Europskom bankom za obnovu i razvoj temeljem kojeg je Podravka d.d. povećala temeljni kapital za iznos od tadašnjih 50 milijuna DEM, a EBRD preuzeo obvezu upisati i uplatiti povlaštene dionice, pri čemu se u potpunosti isključilo pravo svih ostalih dioničara na prvenstvo pri upisu novih dionica (Godišnje izvješće Podravka d.d., 1999, str. 77-78). Tim ugovorom predviđeno je izvršiti upis i uplatu dionica u dvije tranše: tranša $A$ u iznosu 30 milijuna DEM i tranša $B$ u iznosu 20 milijuna DEM.

Ukupno ulaganje od 50 milijuna DEM EBRD je uplatio tako da je obrok $A$ u iznosu od 30 milijuna DEM uplaćen krajem 1998. godine, a obrok B u iznosu od 20 milijuna DEM 8. lipnja 1999. godine, čime se temeljni kapital Podravke d.d. povećao za 190.800.000 kuna. Upisom 636,000 konvertibilnih povlaštenih dionica EBRD je stekao pravo udjela od 10.53 $\%$ temeljnog kapitala.

Glavne karakteristike povlaštenih dionica EBRD-ja u Podravki d.d. su bile kako slijedi: i) povlaštena dividenda po dionici od 6.00 DEM prve 3 godine te $8.50 \mathrm{DEM}$ sve godine kasnije, koje uzimajući u obzir nominalnu vrijednost dionice Podravke od 300 kuna po dionici daju prinos od nekih $8.0 \%$, ii) unutar 5 godina moguća je konverzija 1:1, što znači da se jedna povlaštena dionica može zamijeniti za jednu redovnu dionicu, iii) u slučaju da EBRD prodaje svoj udio, Podravka ima pravo prvokupa, iv) EBRD u određenim situacijama može tražiti ubrzani otkup, v) u slučaju nemogućnosti prodaje povlaštenih dionica ili stečaja Podravke d.d., Podravka je dužna isplatiti predmetnu kupovnu cijenu.

U dodatku na sve gore navedene elemente, u Ugovoru o kupnji povlaštenih dionica navedeno je da se: i) Podravka mora držati određenih financijskih pokazatelja: pokazatelja tekuće likvidnosti, pokazatelja profitabilnosti i neto vrijednosti materijalne imovine, ii) EBRD ima pravo imenovanja člana nadzornog odbora. 
Imenovanje člana nadzornog od strane imatelja povlaštenih dionica nije uobičajena poslovna praksa, ali pretpostavka je, s obzirom na visinu udjela te značaj i utjecaj EBRDja, da se EBRD bio u mogućnosti izboriti za ovakvu mogućnost. EBRD izlazi iz Podravke u srpnju 2003. Povlaštene dionice se poništavaju i za taj iznos se smanjuje temeljni kapital.

\subsection{Proces izdavanja dionica: privatno izdanje / IPO / SPO}

U procesu izdavanja dionica mogu se koristiti tri načina, odnosno modela: i) izdavanje dionica privatnom ponudom, ii) inicijalnom javnom ponudom (,initial public offering“ ili „IPO“), iii) sekundarnom javnom ponudom („secondary public offering“ ili „SPO“) (Orsag, 1997, str. 149).

Privatna ponuda (eng. private placement). Kod privatne ponude poziv na upis dionica dostavlja se samo određenom, ograničenom broju ulagatelja. Uglavnom se tu radi o institucionalnim ulagateljima (kao što su mirovinski fondovi, osiguravateljska društva i dr.), kvalificiranim ulagateljima, postojećim dioničarima, zaposlenicima i slično.

Inicijalna javna ponuda (IPO). Kod inicijalne javne ponude dionica ona predstavlja prvu javnu ponudu dionica nekog društva prema investicijskoj javnosti.

Proces inicijalne javne ponude. Sam proces inicijalne javne ponude može se prikazati kako slijedi: i) prvo se planira proces inicijalne javne ponude (vrijeme, iznos, ciljana cijena i dr.), ii) zatim se odabire financijski te pravni savjetnik koji će dati potrebne instrukcije vezano na financijske i pravne aspekte cijelog procesa, iii) nakon toga pristupa se izradi prospekta i isti se dostavlja na odobrenje od strane regulatora. U Republici Hrvatskoj to je Hrvatska agencija za nadzor financijskih usluga (HANFA), iv) nakon dobivanja odobrenja radi se promocija ponude dionica, tzv. „road show”, v) po završetku promocije i dobivanja povratnih informacija s tržišta vezano za interes za upis dionica pristupa se određivanju konačne cijene ponude, vi) nakon kompletiranja upisa dionice se uvrštavaju na jednu od burzi, bilo domaću Zagrebačku burzu, bilo na jednu od europskih burzi, u Beču, Frankfurtu, Londonu ili, naprimjer, u SAD-u u New Yorku.

Sekundarna javna ponuda (SPO). Pod sekundarnom javnom ponudom podrazumijeva se: i) prodaja dionica od postojećih dioničara ili ii) prodaja novih, novoizdanih dionica (Brealey, Myers, Marcus, 2007, str. 31).

I inicijalnu i sekundarnu javnu ponudu karakteriziraju: i) relativno visoki troškovi izdavanja u odnosu na druge vidove financiranja (kredit) (Šeba Grubišić, Orsag, 2015, str. 105) te ii) relativno dugotrajan proces koji može trajati tjednima i mjesecima.

IPO: prednosti i nedostaci

Proces inicijalne javne ponude ima svoje prednosti i nedostatke.

Kao moguće prednosti mogu se navesti: i) velika, raznolika skupina investitora za prikupljanje kapitala, ii) mogućnost pribavljanja velike količine kapitala za razvoj i širenje poslovanja, iii) veća izloženost društva, prestiž i javni imidž, što može pomoći prodaji društva i povećanju dobiti, iv) olakšavanje akvizicija (zamjena dionica) te v) mogućnost pribavljanja znatno većeg iznosa novca za društvo u usporedbi s drugim opcijama.

Vezano za nedostatke inicijalne javne ponude, o njima se može govoriti zbog ovih razloga: i) dioničko društvo postaje obvezno otkriti financijske, računovodstvene, porezne i druge poslovne informacije, ii) značajni zakonodavni, računovodstveni i marketinški troškovi, iii) 
povećano vrijeme, napor i pažnja potrebna za korporativnim upravljanjem i transparentnim poslovanjem, disciplina (izvještavanje), iv) rizik da potrebna sredstva neće biti prikupljena ako tržište ne prihvati cijenu IPO-a, i v) javno širenje informacija koje mogu biti korisne za konkurente, dobavljače i kupce.

\section{Sudionici u procesu izdavanja dionica}

U procesu izdavanja dionica postoje sljedeći sudionici: i) dioničko društvo izdavatelj, ii) pokrovitelj uvrštenja ili agent izdanja, a to može biti banka ili investicijski savjetnik, iii) regulator, HANFA, koji odobrava prospekt, iv) market makeri / specijalisti, koji se obvezuju održavati razinu ponude i potražnje vrijednosnog papira tako što su spremni istovremeno kupovati i prodavati propisane količine u maksimalnom dozvoljenom „spreadu“ (razlici između kupovne i prodajne cijene), i na kraju, v) kupci dionica: domaći i strani institucionalni investitori (osiguravajuća društva, mirovinski fondovi, banke), druga poduzeća, fizičke osobe i dr.

\section{IPO / SPO U HRVATSKOJ U RAZDOBLJU 2006. DO 2020. GODINE}

Na priloženoj slici prikazane su inicijalne ponude dionica u Republici Hrvatskoj u zadnjih 14 godina. Vidi se da je u razdoblju prije samog izbijanja recesije 2008-2009. godine realizirana većina inicijalnih javnih ponuda. Nakon izbijanja krize aktivnost na tom polju potpuno zamire i prva inicijalna javna ponuda događa se tek 2014. godine s dionicama društva Granolio d.d.

Slika 2. IPO / SPO u Hrvatskoj u razdoblju 2006. do 2020. godine
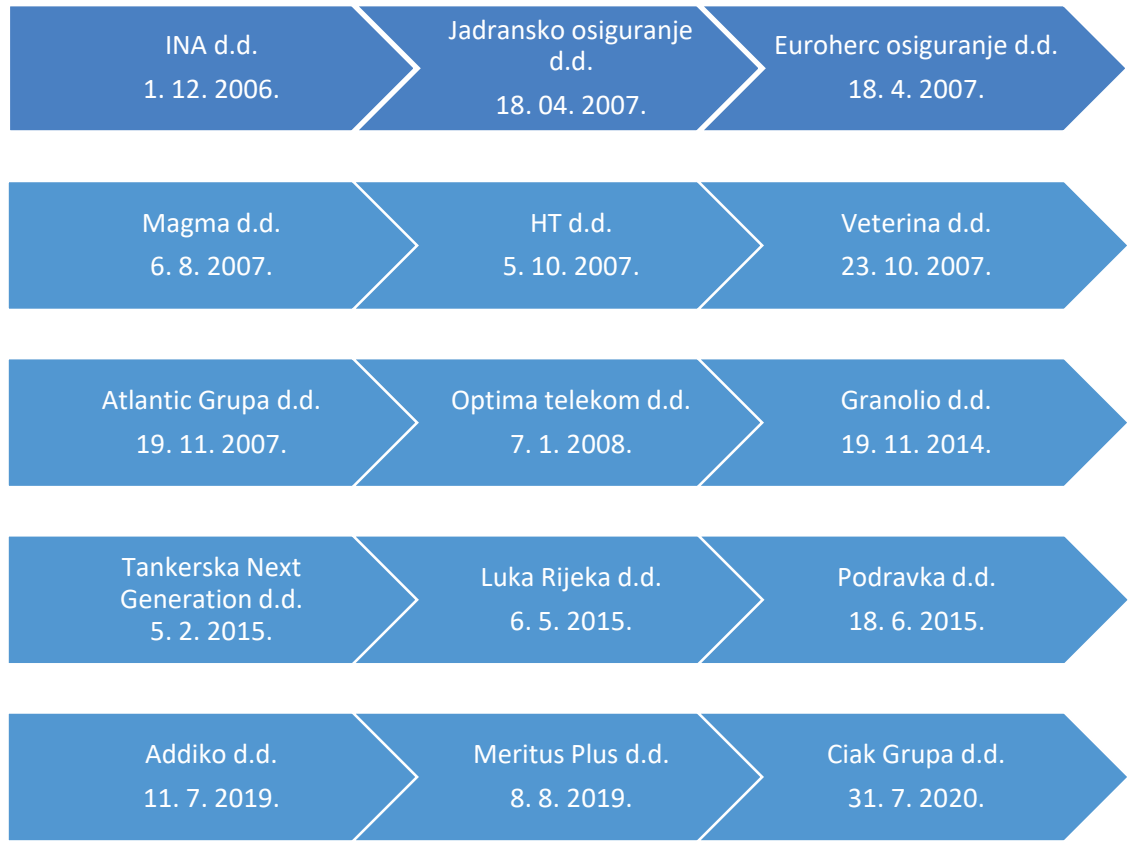

Izvor: Zagrebačka burza d.d., www.zse.hr, izrada autora 
Uzimajući u obzir činjenicu da se vrlo malo poduzeća u RH odlučuje na prikupljanje financiranja putem IPO-a ili SPO-a, neki su skloni karakterizirati hrvatsko tržište kapitala kao sekundarno financijsko tržište (Šeba Grubišić, 2017, str. 52). Ide se i dalje i kaže da je hrvatsko tržište kapitala dominantno kao tržište za promjenu vlasništva i vlasničku koncentraciju. Neki IPO-i koji su se događali tijekom 2006. i 2007. godine odnosili su se na uvjete kada je država prodavala svoje udjele u nekim poduzećima (npr. HT d.d., INA d.d.) i nije se radilo o ulasku svježeg kapitala u poduzeća. Jedan od značajnijih razloga za uvrštavanje na burze su i reputacijski razlozi (Šeba Grubišić, 2017, str. 52). Listanje na burzi uključuje relativno niske (direktne) troškove oglašavanja koje sporadično privuče pozornost poslovnih medija i dioničara.

Infobip d.o.o. - planirani IPO

Jedno od rijetkih većih poduzeća u Republici Hrvatskoj koje razmatra inicijalnu javnu ponudu u naredne jednu do dvije godine je Infobip d.o.o. sa sjedištem u Vodnjanu. Infobip je globalna IT i telekomunikacijska tvrtka koja pruža usluge mobilnih komunikacija u oblaku (eng. cloud) za poslovne korisnike. Portfelj čine profesionalna rješenja za obradu i dostavu SMS i glasovnih poruka, telefonskih poziva, push notifikacija, e-maila te poruka putem popularnih messaging aplikacija. Na popisu klijenata su društvene mreže, internetske kompanije, mobilne „messaging“ aplikacije, banke, marketinške agencije i korporacije, kao i neprofitne organizacije i javne ustanove.

Infobip je osnovan 2002. godine s minimalnim osnivačkim kapitalom od 12.500 eura. Danas Infobip zapošljava oko 3500 zaposlenih, ima 65 ureda diljem svijeta i globalno ga koristi 370 banaka. U 2019. godini Infobip je imao prihode od nekih 600 milijuna eura, odnosno oko 4,5 milijardi kuna. Rast prihoda je fascinantan, što se vidi iz detalja da su u razdoblju od 7 godina došli do ukupnih prihoda od 100 milijuna dolara. U zadnjih 5 godina prosjek rasta im je bio $40 \%$, a u pojedinim godinama i $140 \%$. Klijenti poduzeća su renomirana imena kao: WhatsApp, Gmail, Viber, Facebook Messenger, Uber, LinkedIn i dr. Poduzeće je osiguralo jedan privatni plasman u 2020. godini. Nakon toga, za neke dvije godine, slijedi uvrštavanje na Njujoršku burzu, a jedan od razloga je što 35 \% prihoda ostvaruju u SAD-u.

\section{ZAKLJUČAK}

Prometi i trgovanja na Zagrebačkoj burzi su značajno smanjeni u odnosu na situaciju koja je bila prije otpočinjanja zadnje financijske krize 2007/2008. godine. Broj trgovanih izdanja na Zagrebačkoj burzi se smanjuje iz godine u godinu. Trenutno je na burzi uvršteno 130 dionica, a u razdoblju od 2008. do danas 151 dionica je delistirana, odnosno izvrštena. Najčešći razlozi povlačenja dionica su skupštinske odluke, stečaj, pripajanja, istiskivanja manjinskih dioničara, a od prošle godine i neispunjavanje obveza transparentnosti propisanih pravilima burze. U toj vrlo izazovnoj situaciji neće biti jednostavno održati interes i zanimanje za listanjem na burzi na uvjetno rečeno konvencionalan način. Najveća, etablirana i najlikvidnija izdanja i dalje će biti prisutna.

Hrvatsko tržište financiranja poslovanja poduzeća je i dalje vrlo bankocentrično i poduzeća i dalje glavninu potreba za financiranjem ne osiguravaju putem burze i tržišta kapitala, nego uzimajući kredite poslovnih i razvojnih banaka. Situacija s pandemijom koronavirusa, koja za posljedicu ima smanjenu gospodarsku aktivnost, dodatno je naštetila mogućim 
planovima poduzeća za osiguravanjem financiranja putem tržišta kapitala. S planiranim oživljavanjem gospodarske aktivnosti ove godine za očekivati je da dio financiranja poduzeća osiguraju preko tržišta kapitala. U dodatku na to, novi trend koji se događa je da će manji start-upovi, uglavnom u tehnološkom i IT sektoru, posegnuti za alternativnim načinima i oblicima prikupljanja sredstava za daljnji rast i razvoj putem crowdfundinga, grupnog financiranja, i tržišta kriptovaluta. Broj izdanja i iznosi su i dalje skromni, ali za očekivati je u narednom razdoblju da će njihov broj rasti i da će alternativni načini jačati i povećavati svoj udjel u strukturi listanja na Zagrebačkoj burzi. 


\title{
FINANCING OF THE COMPANY'S BUSINESS BY SHARE EMISSION - OVERVIEW AND TRENDS IN THE REPUBLIC OF CROATIA
}

\author{
Assoc. prof. Ante Rončević, PhD \\ University North \\ Trg dr. Žarka Dolinara 1, 48000 Koprivnica, Croatia \\ Phone: +385 91 1702964, e-mail: aroncevic@unin.hr \\ Josip Vuković, univ. spec. oec., lecturer \\ University North \\ Trg dr. Žarka Dolinara 1, 48000 Koprivnica, Croatia \\ Phone: +38598 9100084, e-mail: jvukovic HYPERLINK \\ “mailto:jvukovic@unin.hr”@unin.hr \\ Assist. prof. Marina Gregorić, Ph.D. \\ University North \\ Trg dr. Žarka Dolinara 1, 48000 Koprivnica, Croatia \\ Phone: +38599 4040164, e-mail: magregoric@unin.hr
}

\begin{abstract}
Enterprises finance their growth and development in different ways, depending on the stage of business of an enterprise At the maturity or expansion stage, there are three predominant ways in which an enterprise can be financed: 1) from retained earnings, 2) by debt financing, and, 3) by issuing shares. The subjects of the research paper are joint stock companies and financing through the issuance of shares. The paper presents the main characteristics and ways of financing business through stock emissions. The paper analyzes types of shares, the issuing process and participants and at the same time describes the elements and processes of the initial and secondary public offering of shares. Financing the operations of companies through preferred shares, which is relatively underrepresented as a means of financing, is shown in a concrete example of the purchase of preferred shares of Podravka plc, by the European Bank for Reconstruction and Development, London. The paper also defines initial and secondary public offerings of shares in the Republic of Croatia since 2006 and in the present.
\end{abstract}

Keywords: financing of the company's operations, securities, shares, preferred shares, stock exchange, initial public offering, secondary public offering 


\section{LITERATURA}

1. Arnerić J., Mateljan M., (2019.), Analiza međuovisnosti tržišta kapitala i tržišta kriptovaluta, Ekonomska misao i praksa, Dbk. God. XXVIII. BR. 2. (449-465)

2. Brealey A. R., Myers C. S., Marcus J. A., (2007.), Osnove korporativnih financija, 5. izdanje, MATE d.o.o., Zagreb

3. Buljat M., Ivanovic Z., Baresa S., (2015.), Analysis of the capital market in Croatia, UTMS Journal of Economics 6 (2): 223-232.

4. Damodaran A., (1997.), Corporate Finance, Theory and Practice, Stern Schoool of Business, New York University, John Wiley \& Sons, Inc,

5. Harrison, R., (2013.), Crowdfunding and the revitalization of the early stage risk capital market: catalyst or chimera. Venture Capital: An International Journal of Entrepreneurial Finance. 15(4), 283311. DOI: 10.1080/13691066.2013.852331

6. Horvatinović T., Silvije O., (2018.), Crowdfunding in a Context of Financing Firms Through Their Life Cycle, Zagreb International Review of Economics \& Business, Vol 1, No1

7. Kolaković M., Turuk M., Turčić I., (2019.), Access to Finance - Experiences of SME in Croatia, Zagreb International Review of Economics \& Business, Vol. 22, Special Conference Issue, pp. 1-14,

8. Orsag S., (1997.), Financiranje emisijom vrijednosnih papira, Zagreb, RIFIN

9. Orsag S., Dedi L., (2011.), Budžetiranje kapitala, Procjena investicijskih projekata, drugo prošireno izdanje Zagreb, MASMEDIA

10. Orsag S., Vrijednosni papiri, (2003.), Revicon, Sarajevo

11. Pepur S., Ćurak M., \& Poposki K., (2016.), Corporate capital structure: the case of large Croatian companies, Economic Research-Ekonomska Istraživanja, 29:1, 498-514

12. Šeba Grubišić M., (2017.), 20 Years of the Croatian Capital Market, Zagreb International Review of Economics \& Business, Vol. 20, Special Conference Issue, pp. 41-58,

13. Šeba Grubišić M., Orsag S., (2015.), Corporate motives for public shares offering during the financial crises, UTMS Journal of Economics 6 (1): 99-114.

14. Šego B., Škrinjarić T., (2018.), Kvantitativna istraživanja Zagrebačke burze-pregled istraživanja od osnutka do 2018. godine, Ekonomski pregled, 69 (6) 655-743

\section{INTERNETSKI IZVORI:}

1. Lider media. htpps://www.lider.media.hr, pristupljeno (10.02.2021)

2. Zagreb Stock Exchange. htpps://www.zse.hr, pristupljeno (10.02.2021)

3. Hanfa. htpps://www.hanfa.hr, pristupljeno (12.02.2021) 